\title{
ONYX OF LONG DURATION
}

BY

\author{
D. J. WOOD
}

CAPE TOWN

Onyx of long duration. Miss C. S., aged 26, came to me asking whether I could remove a white mark from her left eye. On casual inspection it looked like a round nebula with a yellow opacity at the lower part. She asserted that it had been there ever since she had measles twenty years ago.

On careful examination one found a round cavity like a double watch glass containing at the lower part some thickish pus which,

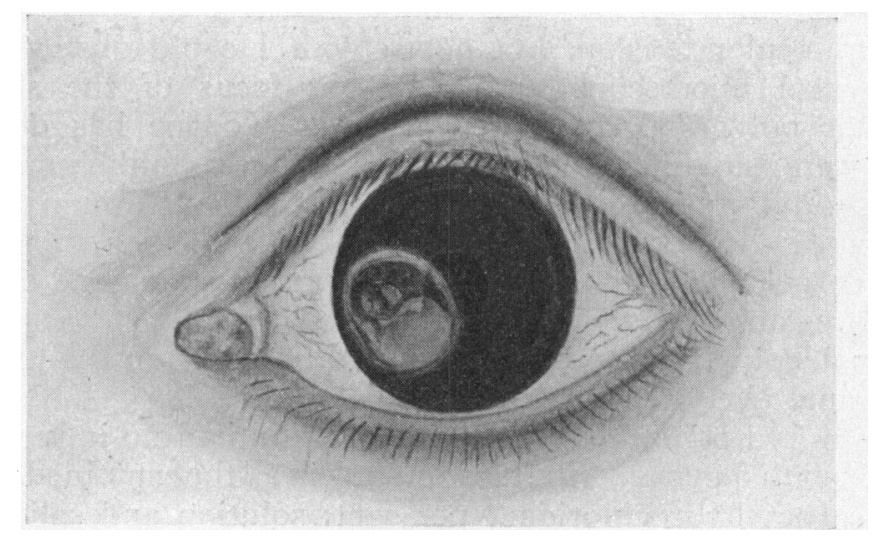

on pressure, changed its shape. The cavity had a clearly defined circular margin and extended from the corneal margin to the inner third of the pupil. The eye was perfectly quiet, there had never been pain, nor was patient conscious that any change had ever occurred. The cavity extended back to Descemet's membrane, and the iris was irregular on its surface behind it. The fundus was visible through the clear part of the cornea, and vision was $6 / 36$.

After watching for some time and vainly trying to photograph it, I took her into hospital and incised the cavity with a discission needle. With a little coaxing and irrigation all the pus was removed, and the eye looked nearly normal. The outline of the cavity remained clearly visible on careful inspection, but was no longer conspicuous. I am not aware of any case where pus has remained in the cornea for so long a period as this. 